Article

\title{
Mycotoxin Production in Liquid Culture and on Plants Infected with Alternaria spp. Isolated from Rocket and Cabbage
}

\section{Ilenia Siciliano ${ }^{1}$, Giuseppe Ortu ${ }^{1, *}$, Giovanna Gilardi ${ }^{1}$, Maria Lodovica Gullino ${ }^{1,2}$ and Angelo Garibaldi ${ }^{1}$}

1 Agroinnova - Centre of Competence for the Innovation in the Agro-Environmental Sector, University of Turin, Largo Paolo Braccini 2, Grugliasco, Turin 10095, Italy;

E-Mails: ilenia.siciliano@unito.it (I.S.); giovanna.gilardi@unito.it (G.G.); marialodovica.gullino@unito.it (M.L.G.); angelo.garibaldi@unito.it (A.G.)

2 DISAFA - Dipartimento di Scienze Agrarie, Forestali e Alimentari, University of Turin, Largo Paolo Braccini 2, Grugliasco, Turin 10095, Italy

* Author to whom correspondence should be addressed; E-Mail: giuseppe.ortu@unito.it; Tel.: +39-011-6708544, Fax: +39-011-6709307.

Academic Editor: Paola Battilani

Received: 19 January 2015 / Accepted: 25 February 2015 / Published: 5 March 2015

\begin{abstract}
Fungi belonging to the genus Alternaria are common pathogens of fruit and vegetables with some species able to produce secondary metabolites dangerous to human health. Twenty-eight Alternaria isolates from rocket and cabbage were investigated for their mycotoxin production. Five different Alternaria toxins were extracted from synthetic liquid media and from plant material (cabbage, cultivated rocket, cauliflower). A modified Czapek-Dox medium was used for the in vitro assay. Under these conditions, more than $80 \%$ of the isolates showed the ability to produce at least one mycotoxin, generally with higher levels for tenuazonic acid. However, the same isolates analyzed in vivo seemed to lose their ability to produce tenuazonic acid. For the other mycotoxins; alternariol, alternariol monomethyl ether, altenuene and tentoxin a good correlation between in vitro and in vivo production was observed. In vitro assay is a useful tool to predict the possible mycotoxin contamination under field and greenhouse conditions.
\end{abstract}

Keywords: Alternaria toxins; HPLC-MS/MS; Eruca sativa; Brassica oleacea 


\section{Introduction}

Alternaria is a common, cosmopolitan fungal genus with several species pathogenic on a wide range of crops, including cereals, vegetables, fruits, ornamentals and oil-seed crops. Several Alternaria spp. produce leaf spots diseases in the field as well as fruit rot in the field and during transit and storage, causing serious economic losses [1]. In addition to incite plant disease, they can act as allergens, affecting immuno-compromised patients [2] and, under suitable conditions, produce powerful toxic secondary metabolites [3] with mutagenic and teratogenic potential, responsible for certain types of cancer. The main Alternaria mycotoxins that occur naturally are tenuazonic acid, alternariol monomethyl ether, alternariol, altenuene, and altertoxin [4]. Based on their chemical structures it is possible to divide Alternaria toxins into five different classes: (1) dibenzo- $\alpha$-pyrones: alternariol (AOH), alternariol monomethyl ether (AME), altenuene (ALT); (2) tetramic acid derivatives: tenuazonic acid (TeA) and iso-tenuazonic acid (iso-TeA); (3) perylene quinones: altertoxins I, II and III (ATX-I, ATX-II and ATX-III) and stemphyltoxin III; (4) AAL-toxins, abbreviation for A. alternata $\mathrm{f}$. sp. lycopersici toxins, including 2 groups, AAL-TA and AAL-TB. The fifth class contains miscellaneous structures such as tentoxin (TEN), a cyclic tetrapeptide. Alternaria toxins have been found in several agricultural commodities [1], including grains [5], sunflower seeds [6], oilseed rape, sorghum, pecans [7].

The production of Alternaria toxins under natural infection or as a consequence of artificial inoculation has been evaluated also in a number of fruit and vegetables, such as apple, tomato, blueberry [8], orange, lemon [9] and mandarin [10].

During the past years, several Alternaria leaf spots have been detected on different vegetable crops, and in most cases the pathogen resulted to be seed-transmitted. For instance, cruciferous plants are frequently damaged by Alternaria spp. and the pathogen is often seed transmitted [11].

In Italy, Alternaria spp. have been recently detected on plants and seeds of wild and cultivated rocket and basil [12,13]; in addition, they are the most common and destructive pathogens of cabbage and cauliflower. Among the known species, A. japonica is reported on wild and cultivated rocket $[14,15]$, Chinese cabbage [16] and turnip [17].

The present study was carried out in order to verify the production of mycotoxins in liquid culture (in vitro) and on cabbage, cultivated rocket (Eruca sativa) and cauliflower (Brassica oleracea), artificially inoculated with several isolates of Alternaria spp. obtained from infected leaves and seeds of different hosts.

\section{Results}

A quantitative assessment of the matrix effect, as proposed by Matuszewski [18], was carried out in order to define what are critical aspects in the quantification of mycotoxins in different matrices. Two sets of samples were prepared: (i) standards of the analytes were dissolved in mobile phase; (ii) the extraction was performed from all matrices (culture medium, cabbage, cauliflower and cultivated rocket) not inoculated with the pathogen and after the analytes were added.

In Table 1 values related to matrix effect showed the higher ionization suppression for TeA, for all matrices. In order to minimize the susceptibility related to matrix effect the quantification of the analytes was obtained through the calibration curves prepared in matrices. 
A third set of samples was prepared to evaluate the recovery; standards were added before extraction procedure at three concentration levels. Three replicates were prepared for each concentration and the average of the results was reported in Table 1.

Table 1. Validation parameters for the matrices object of study.

\begin{tabular}{|c|c|c|c|c|c|}
\hline \multirow{2}{*}{ Validation parameters } & TeA & AOH & AME & ALT & TEN \\
\hline & \multicolumn{5}{|c|}{ LIQUID COLTURE } \\
\hline Recovery $(\%) \pm \mathrm{SD}$ & $79.9 \pm 4.8$ & $81.4 \pm 8.5$ & $86.0 \pm 11.2$ & $100 \pm 5.8$ & $79.9 \pm 4.8$ \\
\hline $\mathrm{LOD}[\mu \mathrm{g} / \mathrm{kg}]$ & 5.79 & 2.31 & 2.20 & 2.31 & 1.34 \\
\hline LOQ $[\mu \mathrm{g} / \mathrm{kg}]$ & 19.3 & 7.69 & 7.35 & 7.69 & 4.45 \\
\hline \multirow[t]{2}{*}{ ME (\%) } & 27.2 & 47.7 & 34.8 & 74.7 & 182 \\
\hline & \multicolumn{5}{|c|}{ CAULIFLOWER } \\
\hline Recovery $(\%) \pm \mathrm{SD}$ & $49.0 \pm 1.3$ & $71.8 \pm 1.6$ & $102 \pm 3.4$ & $85.0 \pm 4.3$ & $51.1 \pm 10.6$ \\
\hline $\mathrm{LOD}[\mu \mathrm{g} / \mathrm{kg}]$ & 8.62 & 6.90 & 4.60 & 7.91 & 8.24 \\
\hline LOQ $[\mu \mathrm{g} / \mathrm{kg}]$ & 28.7 & 23.0 & 15.3 & 26.4 & 27.5 \\
\hline \multirow[t]{2}{*}{$\operatorname{ME}(\%)$} & 16.5 & 52.1 & 58.4 & 67.1 & 44.4 \\
\hline & \multicolumn{5}{|c|}{ CABBAGE } \\
\hline Recovery $(\%) \pm$ SD & $41.3 \pm 3.3$ & $83.5 \pm 3.4$ & $103 \pm 5.0$ & $93.4 \pm 3.3$ & $57.8 \pm 7.5$ \\
\hline $\mathrm{LOD}[\mu \mathrm{g} / \mathrm{kg}]$ & 10.8 & 3.78 & 1.94 & 5.87 & 18.2 \\
\hline LOQ $[\mu \mathrm{g} / \mathrm{kg}]$ & 35.9 & 12.6 & 6.46 & 19.6 & 60.7 \\
\hline \multirow[t]{2}{*}{$\operatorname{ME}(\%)$} & 17.8 & 84.8 & 59.9 & 57.7 & 95.9 \\
\hline & \multicolumn{5}{|c|}{ CULTIVATED ROCKET } \\
\hline Recovery $(\%) \pm \mathrm{SD}$ & $43.0 \pm 5.4$ & $62.1 \pm 2.8$ & $73.6 \pm 2.6$ & $76.4 \pm 1.1$ & $62.1 \pm 1.7$ \\
\hline $\mathrm{LOD}[\mu \mathrm{g} / \mathrm{kg}]$ & 13.8 & 6.31 & 6.46 & 5.84 & 1.36 \\
\hline LOQ $[\mu \mathrm{g} / \mathrm{kg}]$ & 46.1 & 21.0 & 21.5 & 19.5 & 4.53 \\
\hline ME (\%) & 17.2 & 54.9 & 58.4 & 51.9 & 93.5 \\
\hline
\end{tabular}

The recovery of the five analytes in the liquid culture medium was in a range between $79.9 \%$ and $100 \%$. The recovery for TeA $(41 \%-49 \%)$ and TEN (51\%-62\%), calculated with external calibration method, was lower in vegetable matrices, and was similar to those obtained for tomato by Asam et al. [19,20] and Liu et al. [21] when they used the external calibration. However, the same authors improved their results using stable isotope dilutions.

Signal-to-noise method was used to determine limits of detection (LOD) and quantification (LOQ) for each matrix. $S / N$ ratio 3:1 was used for the determination of LOD, while 10:1 for LOQ.

\subsection{Quantification of Mycotoxins in Vitro}

A total of 28 Alternaria strains were analyzed for mycotoxin production. A high percentage ( $>80 \%)$ of tested strains were able to produce at least one mycotoxin (Table 2).

Thirty-six percent of the isolates showed the ability to produce simultaneously four mycotoxins (TeA, AOH, AME and ALT) but not tentoxin. Another group (14\%) produced all investigated mycotoxins. Seven strains (25\%) did not show the capability to produce any mycotoxins. Furthermore, five strains $(18 \%)$ produced only TeA and two strains $(7 \%)$ produced three mycotoxins (TeA, $\mathrm{AOH}$ and AME) (Table 2). 
Table 2. Profile of mycotoxins produced by Alternaria spp. in liquid cultures (in vitro).

\begin{tabular}{cccccc}
\hline Alternaria & \multicolumn{5}{c}{ Mycotoxin Quantification $[\boldsymbol{\mu g} / \mathbf{k g}]$} \\
\cline { 2 - 6 } Code Number & TeA & AOH & AME & ALT & TEN \\
\hline Cav 2/10 & $5980 \pm 791$ & $37.8 \pm 9.50$ & $11.7 \pm 0.7$ & $161 \pm 18.9$ & N.D. $^{\text {a }}$ \\
Cav 3/10 & $2160 \pm 16.1$ & $13.8 \pm 2.21$ & $11.4 \pm 0.3$ & $47.2 \pm 10.8$ & $11.2 \pm 1.72$ \\
Cav 5/10 & $7140 \pm 446$ & $2.82 \pm 0.30$ & $11.9 \pm 0.5$ & $745 \pm 13.1$ & N.D. \\
Cav 7/10 & $63.3 \pm 1.64$ & $3.20 \pm 0.31$ & $4.20 \pm 0.12$ & $126 \pm 37.5$ & N.D. \\
Cav 12/10 & $3210 \pm 68.1$ & $120 \pm 12.9$ & $8.87 \pm 0.65$ & $171 \pm 29.5$ & $16.0 \pm 3.04$ \\
Cav 15/10 & $2330 \pm 408$ & $118 \pm 13.5$ & $9.73 \pm 0.09$ & $319 \pm 17.3$ & N.D. \\
Ruc 1/10 & $1310 \pm 149$ & $42.0 \pm 7.42$ & $12.4 \pm 2.11$ & $102 \pm 8.3$ & N.D. \\
Ruc 2/10 & $51.6 \pm 17.7$ & $1280 \pm 139$ & $851 \pm 44.6$ & $8330 \pm 520$ & N.D. \\
Ruc 3/10 & $24.9 \pm 12.6$ & N.D. & N.D. & N.D. & N.D. \\
Ruc 4/10 & $7240 \pm 1090$ & $90.2 \pm 18.1$ & $4.73 \pm 0.58$ & N.D. & N.D. \\
Ruc 5/10 & $6570 \pm 585$ & $104 \pm 32.1$ & $11.9 \pm 2.17$ & N.D. & N.D. \\
Ruc 6/10 & $1540 \pm 337$ & N.D. & N.D. & N.D. & N.D. \\
Ruc 9/10 & $4900 \pm 447$ & $147 \pm 37.6$ & $16.8 \pm 2.37$ & $433 \pm 33.7$ & $3.13 \pm 0.95$ \\
Ruc 12/10 & $4930 \pm 578$ & $65.9 \pm 17.5$ & $11.2 \pm 1.00$ & $292 \pm 46.9$ & $4.24 \pm 1.31$ \\
Ruc 13/10 & $5840 \pm 324$ & $22.1 \pm 0.62$ & $19.4 \pm 0.84$ & $465 \pm 14.0$ & N.D. \\
Ruc 1/11 & N.D. & N.D. & N.D. & N.D. & N.D. \\
Ruc PMP 4 & $13.6 \pm 3.76$ & N.D. & N.D. & N.D. & N.D. \\
Ruc PMP 8 & $164 \pm 23.5$ & N.D. & N.D. & N.D. & N.D. \\
Ruc PMP 9 & $970 \pm 31.1$ & $264 \pm 38.1$ & $474 \pm 21.5$ & $30,800 \pm 740$ & N.D. \\
Ruc PMP 12 & $3510 \pm 270$ & $72.3 \pm 10.0$ & $21.1 \pm 2.08$ & $270 \pm 39.6$ & N.D. \\
Ruc PMP 19 & $17.0 \pm 3.13$ & N.D. & N.D. & N.D. & N.D. \\
Q36-4NL & N.D. & N.D. & N.D. & N.D. & N.D. \\
Q37-16NL & N.D. & N.D. & N.D. & N.D. & N.D. \\
Q38-1NL & $18.8 \pm 2.82$ & $5.69 \pm 2.98$ & $7.82 \pm 0.96$ & $1040 \pm 25.5$ & N.D. \\
Q38-9NL & N.D. & N.D. & N.D. & N.D. & N.D. \\
Q38-19NL & N.D. & N.D. & N.D. & N.D. & N.D. \\
Q43-1NL & N.D. & N.D. & N.D. & N.D. & N.D. \\
Q43-2NL & N.D. & N.D. & N.D. & N.D. & N.D. \\
\hline
\end{tabular}

${ }^{\mathrm{a}}$ N.D. $=$ not detected. Mean values \pm standard error of three independent biological experiments consisting of three technical replicates each.

TeA, the main toxin produced, has been found in $75 \%$ of tested isolates and only seven strains did not show the ability to produce this mycotoxin. High variability existed referring to mycotoxin concentrations, ranging from 13.6 to $7240 \mu \mathrm{g} / \mathrm{kg}$.

The benzopyrone derivatives (AOH, AME and ALT) (Table 2) were synthesized by almost the same strains. $\mathrm{AOH}$ and AME were produced by about $57 \%$ and ALT by $50 \%$ of the analyzed strains. On the contrary, the mycotoxin concentrations showed different trend among the same strain. In fact, $\mathrm{AOH}$ levels varies from 2.82 to $1280 \mu \mathrm{g} / \mathrm{kg}$, AME from 4.20 to $851 \mu \mathrm{g} / \mathrm{kg}$ and ALT from 47.2 to $30,800 \mu \mathrm{g} / \mathrm{kg}$.

Finally, TEN was detected in only 4 samples. The concentrations were very low (from 3.13 up to $16.0 \mu \mathrm{g} / \mathrm{kg}$ ) when compared with the other mycotoxins. 


\subsection{Disease Severity}

All isolates of Alternaria spp. artificially inoculated on cultivated rocket showed a moderate disease severity with the exception of Ruc $5 \backslash 10$, that showed a low value of disease severity (Table 3 ). Generally, the tested isolates caused only slight leaf necrosis and low virulence on both cabbage and cauliflower, with the exception of Cav $7 \backslash 10$ and Cav $3 \backslash 10$ that produce severe leaf spot symptoms on cauliflower (Table 3).

Table 3. Disease severity caused by isolates of Alternaria spp. tested for mycotoxin production.

\begin{tabular}{|c|c|c|c|}
\hline Isolate & Host & $\%$ Affected Leaf Area & Reaction $^{\text {a }}$ \\
\hline Cav $2 \backslash 10$ & Cauliflower & 12.5 & $\mathrm{~L}$ \\
\hline Cav $3 \backslash 10$ & Cauliflower & 55 & $\mathrm{H}$ \\
\hline Cav $5 \backslash 10$ & Cauliflower & 27.5 & $\mathrm{~L}$ \\
\hline Cav $7 \backslash 10$ & Cauliflower & 57.5 & $\mathrm{H}$ \\
\hline Cav $12 \backslash 10$ & Cauliflower & 25 & $\mathrm{~L}$ \\
\hline Cav $2 \backslash 10$ & Cabbage & 15 & $\mathrm{~L}$ \\
\hline Cav $3 \backslash 10$ & Cabbage & 20 & $\mathrm{~L}$ \\
\hline Cav $5 \backslash 10$ & Cabbage & 15 & $\mathrm{~L}$ \\
\hline Cav $7 \backslash 10$ & Cabbage & 10 & $\mathrm{~L}$ \\
\hline Cav $12 \backslash 10$ & Cabbage & 20 & $\mathrm{~L}$ \\
\hline Ruc PMP 12 & Cultivated rocket & 34 & M \\
\hline Ruc PMP 19 & Cultivated rocket & 34 & M \\
\hline Ruc $3 \backslash 10$ & Cultivated rocket & 30 & M \\
\hline Ruc $4 \backslash 10$ & Cultivated rocket & 40 & M \\
\hline Ruc $5 \backslash 10$ & Cultivated rocket & 26 & $\mathrm{~L}$ \\
\hline Ruc $6 \backslash 10$ & Cultivated rocket & 36 & M \\
\hline Ruc $12 \backslash 10$ & Cultivated rocket & 42 & M \\
\hline Ruc $13 \backslash 10$ & Cultivated rocket & 40 & M \\
\hline
\end{tabular}

a Reaction: NP, non-pathogenic strain; L, low virulence $(10 \%-30 \%)$; M, moderate virulence $(31 \%-50 \%)$; $\mathrm{H}$, high virulence $(51 \%-100 \%)$.

\subsection{Quantification of Mycotoxin in Vivo}

TeA was detected only in two samples, each one of rocket and cauliflower. Also TEN was detected only in a few samples, one of cabbage and two of cauliflowers. However, the benzopyrone derivatives $(\mathrm{AOH}, \mathrm{AME}$ and ALT) were detected in some samples of rocket and in all samples of cabbage and cauliflower (Table 4).

Tenuazonic acid production in vivo was very low opposed to what was found in the in vitro studies; only one strain from rocket (Ruc 6/10) and one from cauliflower (Cav 5/10) were positive. The production of AOH, AME and ALT was similar in vivo (Table 4) as in vitro (Table 2); the strains that did not produce mycotoxins in vitro were negative also in vivo, those which were positive in vitro were also positive in the majority of samples tested in vivo. Indeed, it was possible to find a positive match for all tested isolates of cabbage and cauliflower, only one strain (Ruc PMP 12) tested on rocket gave deviating results for the production of AOH and ALT. The production of TEN was very low both in vitro and in vivo. However, two strains (Ruc 12/10 and Cav 12/10) resulted in an opposite trend. 
Table 4. Mycotoxins produced by Alternaria spp. in in vivo samples.

\begin{tabular}{|c|c|c|c|c|c|}
\hline Isolate & TeA & АОН & AME & ALT & TEN \\
\hline \multicolumn{6}{|c|}{ CAULIFLOWER $[\mu \mathrm{g} / \mathrm{kg}]$} \\
\hline Cav $2 / 10$ & N.D. ${ }^{a}$ & $16.7 \pm 6.77$ & $32.11 \pm 4.8$ & $444 \pm 22.0$ & N.D. \\
\hline Cav 3/10 & N.D. & $2050 \pm 93.6$ & $373 \pm 29.1$ & $391 \pm 47.0$ & $20.5 \pm 4.28$ \\
\hline Cav 5/10 & $475 \pm 56.7$ & $94.5 \pm 9.57$ & $6.72 \pm 1.71$ & $254 \pm 61.9$ & N.D. \\
\hline Cav 7/10 & N.D. & $3.83 \pm 0.11$ & $593 \pm 32.7$ & $865 \pm 86.7$ & N.D. \\
\hline Cav 12/10 & N.D. & $10.8 \pm 2.27$ & $12.1 \pm 2.09$ & $102 \pm 17.3$ & N.D. \\
\hline \multicolumn{6}{|c|}{ CABBAGE $[\mu \mathrm{g} / \mathrm{kg}]$} \\
\hline Cav 2/10 & N.D. & $8.0 \pm 0.71$ & $13.3 \pm 4.0$ & $82.8 \pm 11.8$ & N.D. \\
\hline Cav $3 / 10$ & N.D. & $1850 \pm 46.5$ & $239.4 \pm 42.3$ & $661 \pm 37.1$ & $1.86 \pm 0.08$ \\
\hline Cav 5/10 & N.D. & $72.5 \pm 13.9$ & $8.47 \pm 0.58$ & $274 \pm 27.5$ & N.D. \\
\hline Cav 7/10 & N.D. & $8.29 \pm 2.35$ & $16.3 \pm 1.20$ & $470 \pm 2.45$ & N.D. \\
\hline Cav $12 / 10$ & N.D. & $6.51 \pm 1.51$ & $2.26 \pm 0.32$ & $435 \pm 27.4$ & $3.98 \pm 0.94$ \\
\hline \multicolumn{6}{|c|}{ CULTIVATED ROCKET $[\mu \mathrm{g} / \mathrm{kg}]$} \\
\hline Ruc PMP 12 & N.D. & N.D. & $3.60 \pm 0.15$ & N.D. & N.D. \\
\hline Ruc PMP 19 & N.D. & N.D. & N.D. & N.D. & N.D. \\
\hline Ruc 3/10 & N.D. & N.D. & N.D. & N.D. & N.D. \\
\hline Ruc 4/10 & N.D. & $311 \pm 14.4$ & $1280 \pm 48.2$ & N.D. & N.D. \\
\hline Ruc 5/10 & N.D. & $16.9 \pm 2.32$ & $4.46 \pm 0.92$ & N.D. & N.D. \\
\hline Ruc 6/10 & $70.0 \pm 15.1$ & N.D. & N.D. & N.D. & N.D. \\
\hline Ruc 12/10 & N.D. & $16.9 \pm 0.77$ & $83.4 \pm 8.48$ & $80.2 \pm 12.5$ & N.D. \\
\hline Ruc $13 / 10$ & N.D. & $125 \pm 2.31$ & $293 \pm 68.4$ & $125 \pm 10.3$ & N.D. \\
\hline
\end{tabular}

Mean values \pm standard error of three independent biological experiments consisting of three technical replicates each. ${ }^{\text {a }}$ N.D. $=$ not detected.

\section{Discussion}

Our results show that different Alternaria sp. isolates from rocket and cabbage plants are able to produce five different mycotoxins under in vitro conditions. Most of the isolates obtained from both host plants were characterized by the production of high quantity of TeA in vitro. However, when tested in vivo, the same isolates lost their ability to produce TeA and in almost all cases it was not possible to detect this mycotoxin. Only two strains produce TeA in vivo: Ruc $6 / 10$ with $70 \mu \mathrm{g} / \mathrm{kg}$ on cultivated rocket and Cav $5 / 10$ but only in cauliflower with $475 \mu \mathrm{g} / \mathrm{kg}$ (Table 4). This is in contrast with other results obtained in previous works. In fact, TeA has been indicated as a major mycotoxin on naturally infected tomato grown in southern Italy, with levels up to $7.2 \mathrm{mg} / \mathrm{g}$ while alternariol and alternariol methyl ether were present at lower levels [22]. Also Stinson et al. [8,9] reported a high level of tenuazonic acid in inoculated and naturally infected tomatoes. In our experiment the different growth conditions (leaf respect fruit) seem able to influence the TeA productions.

Several isolates of Alternaria spp. were identified as producers of alternariol and of alternariol methyl ether, both in liquid media and in solid rice medium [23]. The mycotoxin production depended on different factors. Sanchis and Magan [24] showed that water activity (aw) played an important role for the TeA, AME and AOH production in A. alternata indicating an optimum value greater than 0.97. Also temperature is an important factor with an optimum at $28{ }^{\circ} \mathrm{C}$ for $\mathrm{AOH}$ and $\mathrm{AME}$ and $21{ }^{\circ} \mathrm{C}$ for 
TEA in synthetic medium for A. alternata [25]. Moreover, light exposure had a strong influence on $\mathrm{AOH}$ with a reduced mycotoxin production when compared to cultures grown in the dark [26,27]. Finally, Brzonkalik et al. [28] showed that cultivation conditions such as carbon and nitrogen source can influence mycotoxin production by A. alternata grown in synthetic medium. Mycotoxin production also depends on the type of plant and cultivar affected, on geographical location where the plant is grown and harvested as well as on climate [29].

For the other four mycotoxins (AOH, AME, ALT and TEN), results showed a correlation between the mycotoxin production under in vitro and in vivo conditions.

\section{Materials and Methods}

\subsection{Isolate Collection and Propagation}

Isolates of Alternaria spp. obtained from leaves (16 isolates) and seeds (12 isolates) of different hosts (cabbage, cauliflower, wild and cultivated rocket) were tested (Tables 5 and 6). All Alternaria isolates were obtained by placing pieces of infected tissue from rocket and cabbage onto potato dextrose agar (PDA) and incubated at $25^{\circ} \mathrm{C}$ for 7 days. The strains were then transferred onto potato carrot agar (PCA) amended with $0.5 \mathrm{mg} / \mathrm{mL}$ streptomycin sulphate, and incubated for 7 days at $25^{\circ} \mathrm{C}$. Single-spore cultures were established for each isolate by serial dilution of conidial suspension; a drop of $10^{-6}$ and $10^{-8}$ dilutions was plated on PDA medium. A single germinated macroconidia ware selected under stereomicroscope and transferred onto a new PDA plate. The tested strains of Alternaria spp. from brassica plants and seeds were identified by morphological observations as well as by a phylogenetic analysis based on $\beta$-tubulin gene and anonymous region OPA10-2 sequences [14].

Table 5. List of the isolates of Alternaria spp. obtained from leaves of different hosts in northern Italy.

\begin{tabular}{cccc}
\hline Isolate Code & Species & Host & Origin \\
\hline Cav $2 / 10$ & A.alternata complex & Cauliflower cv. White excell & Boves (CN) \\
Cav $3 / 10$ & A.alternata complex & Cabbage cv. Morama & Moncalieri (TO) \\
Cav $5 / 10$ & A. arborescens & Cabbage cv.Estoryl & Asti (AT) \\
Cav $7 / 10$ & A.alternata complex & Cabbage cv. Morama & Savigliano (CN) \\
Cav $12 / 10$ & A.alternata complex & Cauliflower cv. White excell & Boves (CN) \\
Cav $15 / 10$ & A.alternata complex & Cabbage cv. Dama & Boves (CN) \\
Ruc $1 / 10$ & A.alternata complex & Cultivated rocket & Moncalieri (TO) \\
Ruc $2 / 10$ & A.alternata complex & Cultivated rocket & Bagnolo (TO) \\
Ruc $3 / 10$ & A.alternata complex & Cultivated rocket & Alessandria (AL) \\
Ruc $4 / 10$ & A.alternata complex & Wild rocket cv. Frastagliata & Albenga (SV) \\
Ruc $5 / 10$ & A. arborescens & Cultivated rocket & Moncalieri (TO) \\
Ruc $6 / 10$ & A.alternata complex & Cultivated rocket & Moncalieri (TO) \\
Ruc $9 / 10$ & A. arborescens & Cultivated rocket & Moncalieri (TO) \\
Ruc $12 / 10$ & A. arborescens & Cultivated rocket & Moncalieri (TO) \\
Ruc $13 / 10$ & A.alternata complex & Cultivated rocket & Moncalieri (TO) \\
Ruc $1 / 11$ & A.alternata complex & Wild rocket & Moncalieri (TO) \\
\hline
\end{tabular}


Table 6. List of the isolates of Alternaria spp. obtained from seeds of different hosts.

\begin{tabular}{cccc}
\hline Isolate Code & Species & Host & Origin \\
\hline Ruc PMP 4 & A. brassicicola & Cultivated rocket & Cesena (FC) \\
Ruc PMP 8 & A.alternata complex & Cultivated rocket & Cesena (FC) \\
Ruc PMP 9 & A.alternata complex & Cultivated rocket & Cesena (FC) \\
Ruc PMP 12 & A.alternata complex & Cultivated rocket & Cesena (FC) \\
Ruc PMP 19 & A. japonica & Cultivated rocket & Cesena (FC) \\
36Q-4NL & A. japonica & Wild rocket & Venezia (VE) \\
37Q-16NL & A. japonica & Wild rocket & Venezia (VE) \\
38Q-1NL & A. japonica & Wild rocket & Lodi (LO) \\
38Q-9NL & A. japonica & Wild rocket & Lodi (LO) \\
38Q-19NL & A. japonica & Wild rocket & Lodi (LO) \\
43Q-1NL & A. japonica & Wild rocket & Azzano (BG) \\
43Q-2NL & A. japonica & Wild rocket & Azzano (BG) \\
\hline
\end{tabular}

\subsection{Secondary Metabolite Production in Vitro}

Production of secondary metabolites was tested for each isolate using a modified Czapek-Dox medium according to Brzonkalik et al. [28]: $10 \mathrm{~g} / \mathrm{L}$ glucose, $0.162 \mathrm{~g} / \mathrm{L} \mathrm{NH}_{4} \mathrm{NO}_{3}, 1.7 \mathrm{~g} / \mathrm{L} \mathrm{KH}_{2} \mathrm{PO}_{4}$, $0.85 \mathrm{~g} / \mathrm{L} \mathrm{MgSO}_{4}, 0.425 \mathrm{~g} / \mathrm{L} \mathrm{NaCl}, 0.425 \mathrm{~g} / \mathrm{L} \mathrm{KCl}, 0.017 \mathrm{~g} / \mathrm{L} \mathrm{FeSO}_{4}, 0.017 \mathrm{~g} / \mathrm{L} \mathrm{ZnSO} 4$ and $1.7 \mathrm{~g} / \mathrm{L}$ yeast extract, $\mathrm{pH}$ 5.5. Cultures were inoculated with three mycelia plugs in $50 \mathrm{~mL}$ of medium. All cultures were performed in triplicate and incubated in the dark at $28^{\circ} \mathrm{C}$. After 8 days, cultures were filtered and the clear medium was analyzed.

\subsection{Mycotoxin Evaluation on Infected Plants}

In order to test in vivo production of mycotoxins, 13 isolates of Alternaria spp., 8 from rocket and 5 from cabbage, were randomly selected and propagated on PCA as previously described. Forty to fifty day-old plants of cultivated rocket, cauliflower and cabbage grown in $2 \mathrm{~L}$ pots were inoculated by spraying a suspension containing conidia and mycelia fragments at $1 \times 10^{5} \mathrm{CFU} / \mathrm{mL}$. Inoculated plants were immediately covered with plastic bags for 7 days and kept in a growth chamber at $23 \pm 1{ }^{\circ} \mathrm{C}$. Non inoculated plants maintained in the same condition were used as control.

Fifteen days after artificial inoculation, the percentage of affected leaf area of 50 leaves was estimated by using a disease index scale ranging from 0 to 5 ; where $0=$ no visible leaf spots; $1=$ up to $10 \%$ leaf area affected; $2=11 \%-25 \%$ leaf area affected; $3=26 \%-50 \%$ leaf area affected; $4=51 \%-75 \%$ leaf area affected; $5=$ more than $75 \%$ or dead leaves [30]. The disease index was converted into percentage. The infected leaves of rocket, cauliflower and cabbage were collected and stored at $-20{ }^{\circ} \mathrm{C}$ for 15 days before starting the evaluation. Disease reactions were assigned as follows: NP, non-pathogenic strain; $\mathrm{L}$, low virulence $(10 \%-30 \%)$; $\mathrm{M}$, moderate virulence $(31 \%-50 \%)$; $\mathrm{H}$, high virulence $(51 \%-100 \%)$.

\subsection{Standard Preparation for Chemical Analysis}

Standards of TeA copper salt from A. alternata (Purity $\geq 98 \%$ ), AOH from Alternaria spp. (Purity $\geq 94 \%$ ), AME from Alternaria alternata (Purity $\geq 98 \%$ ), ALT from Alternaria spp. (Purity $\geq 98 \%$ ) 
and TEN from Alternaria tenuis (Purity 99\%) were purchased from Sigma-Aldrich in crystallized form. A stock solution of $1000 \mu \mathrm{g} / \mathrm{mL}$ and a working solution of $10 \mu \mathrm{g} / \mathrm{mL}$ were prepared in methanol for each molecule and kept at $-20{ }^{\circ} \mathrm{C}$. Standards for HPLC calibration and standards for addition experiment were prepared by diluting the working solution.

\subsection{Extraction of Secondary Metabolites from Fungal Cultures}

Alternaria mycotoxins were extracted by liquid-liquid extraction. Each sample was adjusted to $\mathrm{pH} 2$ with $\mathrm{HCl}$ and an aliquot $(5 \mathrm{~mL})$ was transferred in a separating funnel. Ten $\mathrm{mL}$ of dichloromethane were added three times and the mixture was shaken for $1 \mathrm{~min}$, then the dichloromethane extracts were collected in a flask. The final extract was evaporated to dryness in a rotary evaporator at $35{ }^{\circ} \mathrm{C}$. The residue was dissolved in $1 \mathrm{~mL}$ of $\mathrm{H}_{2} \mathrm{O}: \mathrm{CH}_{3} \mathrm{OH}$ 1:1 for the HPLC-MS/MS analysis.

\subsection{Extraction of Secondary Metabolites from Plant Material}

Alternaria mycotoxins were extracted by solid-liquid extraction following a method described by Noser et al. [31]. All samples were homogenized and stored in a refrigerator at $-20{ }^{\circ} \mathrm{C}$ until extraction. $1 \mathrm{~g}$ of each homogenized sample was placed in a centrifuge tube with $0.5 \mathrm{~g}$ of $\mathrm{NaCl}$ and $10 \mathrm{~mL}$ of extraction solution $\left(\mathrm{CH}_{3} \mathrm{OH}: \mathrm{CH}_{3} \mathrm{CN}: \mathrm{H}_{2} \mathrm{O}\right.$ 10:45:45 $v / v / v$ adjusted to $\mathrm{pH} 3$ with o-phosphoric acid) was added. The mixture was shaken for $30 \mathrm{~min}$ in an ultrasonic bath and then centrifuged at $5000 \mathrm{rpm}$ for $5 \mathrm{~min}$.

Solid phase extraction was performed using hydrophilic lipophilic balanced (HLB) copolymer cartridges (Polyntell AttractSPETM W/O $3 \mathrm{~mL}, 60 \mathrm{mg}$ ). First, $2 \mathrm{~mL}$ of clarified extract was diluted with $18 \mathrm{~mL}$ of $\mathrm{HCl} 0.01 \mathrm{~N}$ then passed through a conditioned cartridge (conditioning was made first with $3 \mathrm{~mL}$ of $\mathrm{CH}_{3} \mathrm{OH}$ followed by $3 \mathrm{~mL}$ of $\mathrm{H}_{2} \mathrm{O}$ ). After a washing step with $3 \mathrm{~mL}$ of water, toxins were eluted with $\mathrm{CH}_{3} \mathrm{OH}: \mathrm{CH}_{3} \mathrm{CN} 70: 30$ acidified with $0.1 \%$ of $\mathrm{CH}_{3} \mathrm{COOH}$. The eluate was dried in vacuum

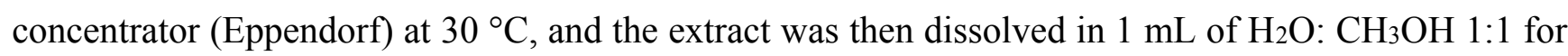
the HPLC-MS/MS analysis.

\subsection{HPLC-MS/MS Analysis of Secondary Metabolites}

All analyses were carried out by using a 1260 Agilent Technologies system consisting of a binary pump and a vacuum degasser, connected to a Varian autosampler Model 410 Prostar (Hansen Way, CA, USA) equipped with a $20 \mu \mathrm{L}$ loop coupled with a Varian 310-MS TQ Mass Spectrometer. The separation of mycotoxins was performed using a Kinetex PFP $(100 \times 2.10 \mathrm{~mm} 2.6 \mu \mathrm{m}$, Phenomenex, Torrance, CA, USA) under a flow of $200 \mu \mathrm{L} / \mathrm{min}$. The column temperature was set at $35^{\circ} \mathrm{C}$. Solvent A was $\mathrm{H}_{2} \mathrm{O}$ with $2 \mathrm{mM} \mathrm{NH}_{4} \mathrm{HCO}_{3}$, solvent $\mathrm{B}$ was $\mathrm{CH}_{3} \mathrm{OH}$ with $2 \mathrm{mM} \mathrm{NH}_{4} \mathrm{HCO}_{3}$. HPLC analysis was performed using a linear gradient from $40 \%$ to $100 \%$ of solvent B in $12 \mathrm{~min}$.

Samples were ionized using an electrospray (ESI) ion source operating in negative ion mode. For the MRM experiments two transitions were selected for each compound: for TeA, $m / z 196>112 \mathrm{CE} 24 \mathrm{~V}$ (monitoring) and $m / z 196>139 \mathrm{CE} 20 \mathrm{~V}$ (quantification); for AME, $m / z 257>147 \mathrm{CE} 34 \mathrm{~V}$ (monitoring) and $\mathrm{m} / z 257>213 \mathrm{CE} 22 \mathrm{~V}$ (quantification); for $\mathrm{AOH}, \mathrm{m} / \mathrm{z} 271>228 \mathrm{CE} 28 \mathrm{~V}$ (monitoring) and $\mathrm{m} / \mathrm{z}$ $271>256 \mathrm{CE} 22 \mathrm{~V}$ (quantification); for ALT, $m / z 291>247 \mathrm{CE} 20 \mathrm{~V}$ (monitoring) and $\mathrm{m} / z 291>229$ 
CE 12V (quantification); for TEN, $m / z 413>141 \mathrm{CE} 18 \mathrm{~V}$ (monitoring) and $m / z 413>271 \mathrm{CE} 16 \mathrm{~V}$ (quantification). The collision gas (Ar) pressure was set at 2 mbar for all experiments.

\section{Conclusions}

The spread of Alternaria leaf spot on rocket and cabbage represents not only a danger for the production chain but also a serious risk for human health. From our results, in vitro assay is a potential tool to predict the possible mycotoxin contamination, except for tenuazonic acid, of these host plants grown in field or under greenhouse conditions.

\section{Acknowledgments}

Work supported by the European Community's Seventh Framework Programme (FP7/2007-2013) under grant agreement $n^{\circ}$ 261752, PLANTFOODSEC "Plant and Food Biosecurity, Network of Excellence".

\section{Author Contributions}

Ilenia Siciliano performed the chemical analysis; Giuseppe Ortu provided the in vitro assay; Giovanna Gilardi provided the pathogenicity assay; Angelo Garibaldi and Maria Lodovica Gullino performed a scientific supervision and manuscript revising; Giuseppe Ortu, Ilenia Siciliano and Giovanna Gilardi analyzed the data and wrote the paper. All authors read and approved the final manuscript.

\section{Abbreviation}

TeA, tenuazonic acid; $\mathrm{AOH}$, alternariol; AME, alternariol monomethyl ether; ALT, altenuene; TEN, tentoxin.

\section{Conflicts of Interest}

The authors declare no conflict of interest.

\section{References}

1. Scott, P.M. Analysis of agricultural commodities and foods for Alternaria mycotoxins. J. AOAC Int. 2001, 84, 1809-1817.

2. Rossman, S.N.; Cernoch, P.L.; Davis, J.R. Dematiaceous fungi are an increasing cause of human disease. Clin. Infect. Dis. 1996, 22, 73-80.

3. Ostry, V. Alternaria mycotoxins: An overview of chemical characterization, producers, toxicity, analysis and occurrence in foodstuffs. World Mycotoxins J. 2008, 1, 175-188.

4. Weidenborner, M. Encyclopedia of Food Mycotoxins; Springer: Dordrecht, The Netherlands, 2001.

5. Häggblom, P.; Stepinska, A.; Solyakov, A. Alternaria mycotoxins in Swedish feed grain. In Proceedings of the 29th Mycotoxin Workshop, Stuttgart-Fellbach, Germany, 14-16 May 2007; p. 35.

6. Logrieco, A.; Bottalico, A.; Visconti, A.; Vurro, M. Natural occurrence of Alternaria mycotoxins in some plant products. Microbiol. Aliment. Nutr. 1988, 6, 13-17. 
7. Schroeder, H.W.; Cole, R.J. Natural occurrence of alternariols in discolored pecans. J. Agric. Food Chem. 1977, 25, 204-206.

8. Stinson, E.E.; Bills, D.D.; Osman, S.F.; Siciliano, J.; Ceponis, M.J.; Heisler, E.G. Mycotoxin production by Alternaria species grown on apples, tomatoes and blueberries. J. Agric. Food Chem. 1980, 28, 960-963.

9. Stinson, E.E.; Osman, S.F.; Heisler, E.J.; Siciliano, J.; Bills, D.D. Mycotoxin production in whole tomatoes, apples, oranges and lemons. J. Agric. Food Chem. 1981, 29, 790-792.

10. Logrieco, A.; Visconti, A.; Bottalico, A. Mandarin fruit rot caused by Alternaria alternata and associated mycotoxins. Plant Dis. 1990, 74, 415-417.

11. Tohyama, A.; Tsuda, M. Alternaria on cruciferous plants. 4. Alternaria species on seed of some cruciferous crops and their pathogenicity. Mycoscience 1995, 36, 257-261.

12. Garibaldi, A.; Gilardi, G.; Bertoldo, C.; Gullino, M.L. First report of leaf spot of wild (Diplotaxis tenuifolia) and cultivated (Eruca sativa) rocket, caused by Alternaria japonica in Italy. Plant Dis. 2011, 95, 1316.

13. Gullino, M.L.; Gilardi, G.; Garibaldi, A. Seed-borne fungal pathogens of leafy vegetable crops. In Global Perspectives on the Health of Seeds and Plant Propagation Material; Gullino, M.L., Munkvold, G., Eds.; Springer: Dordrecht, The Netherlands, 2014; pp. 47-56.

14. Gilardi, G.; Demarchi, S.; Ortu, G.; Gullino, M.L.; Garibaldi, A. Occurrence of Alternaria japonica on seeds of wild and cultivated rocket. J. Phytopathol. 2014, doi:10.1111/jph.12292.

15. Tidwell, T.E.; Blomquist, C.L.; Rooney-Latham, S.; Scheck, H.J. Leaf spot of arugula, caused by Alternaria japonica, in California. Plant Dis. 2014, 98, 1272.

16. Ren, X.X.; Zhang, G.Z.; Dai, W.A. First report of damping-off caused by Alternaria japonica on chinese cabbage seedlings in China. Plant Dis. 2012, 96, 1378.

17. Bassimba, D.D.M.; Mira, J.L.; Vicent, A. First report of Alternaria japonica causing black spot of turnip in Spain. Plant Dis. 2013, 97, 1505.

18. Matuszewski, B.K.; Constanzer, M.L.; Chavez-Eng, C.M. Strategies for the Assessment of Matrix Effect in Quantitative Bioanalytical Methods Based on HPLC-MS/MS. Anal. Chem. 2003, 75, 3019-3030.

19. Asam, S.; Liu, Y.; Konitzer, K.; Rychlik, M. Development of a stable isotope dilution assay for tenuazonic acid. J. Agric. Food Chem. 2011, 59, 2980-2987.

20. Asam, S.; Lichtenegger, M.; Liu, Y.; Rychlik, M. Content of the Alternaria mycotoxin tenuazonic acid in food commodities determined by a stable isotope dilution assay. Mycotoxin Res. 2012, 28, 9-15.

21. Liu, Y.; Rychlik, M. Development of a stable isotope dilution LC-MS/MS method for the Alternaria toxins tentoxin, dihydrotentoxin and isotentoxin. J. Agric. Food Chem. 2013, 61, 2970-2978.

22. Bottalico, A.; Logrieco, A. Toxigenic Alternaria species of economic importance. In Mycotoxins in Agriculture and Food Safety; Sinha, K.K., Bhatnagar, D., Eds.; Marcel Dekker: New York, NY, USA, 1998; pp. 65-108.

23. Mass, M.R.; Woody, M.A.; Chu, F.S. Production of alternariol and alternariol methyl ether by Alternaria spp. J. Food Saf. 1981, 3, 39-47. 
24. Sanchis, V.; Magan, N. Environmental conditions affecting mycotoxins. In Mycotoxins in Food: Detection and Control; Magan, N., Olsen, M., Eds.; Woodhead Publishing: Cambridge, UK, 2004; pp. 174-189.

25. Hasan, H.A. Alternaria mycotoxins in black rot lesion of tomato fruit: Conditions and regulation of their production. Acta Microbiol. Immunol. Hung. 1996, 43, 125-133.

26. Häggblom, P.; Niehaus, W.G. Light effects on polyketide metabolism in Alternaria alternata. Exp. Mycol. 1986, 10, 252-255.

27. Häggblom, P.; Unestam, T. Blue light inhibits mycotoxin production and increases total lipids and pigmentation in Alternaria alternata. Appl. Environ. Microbiol. 1979, 38, 1074-1077.

28. Brzonkalik, K.; Herrling, T.; Syldatk, C.; Neumann, A. The influence of different nitrogen and carbon sources on mycotoxin production in Alternaria alternata. Int. J. Food Microbiol. 2011, 147, 120-126.

29. Lauren, S.J. Fadwa Al-Taher Factors affecting mycotoxin production in fruits. In Mycotoxins in Fruit and Vegetables; Barkai-Golan, R., Paster, N., Eds.; Academic Press Is an Imprint of Elsevier: London, UK, 2008; pp. 75-104.

30. Vakalounakis, D.J. Evaluation of tomato cultivars for resistance to Alternaria blight. Ann. Appl. Biol. 1983, 102, 138-139.

31. Noser, J.; Schneider, P.; Rother, M.; Schmutz, H. Determination of six Alternaria toxin with UPLC-MS/MS and their occurrence in tomatoes and tomato products from the Swiss market. Mycotoxin Res. 2011, 4, 265-271.

(C) 2015 by the authors; licensee MDPI, Basel, Switzerland. This article is an open access article distributed under the terms and conditions of the Creative Commons Attribution license (http://creativecommons.org/licenses/by/4.0/). 